\title{
An observation of the peer-assisted learning (PAL) method in the clinical teaching of vertigo/ dizziness-related diseases for standardized residency training (SRT) students in China: a randomized, controlled, multicenter study
}

Xu Rui ${ }^{1 \dagger}$, Duan Chunmei ${ }^{1 \dagger}$, He Qian ${ }^{1 \dagger}$, Meng Zhaoyou ${ }^{1}$, Wang Gong ${ }^{1}$, Liu Shu' ${ }^{1}$, Guo Meng ${ }^{2}$, Chen Xiaoyan ${ }^{1}$, Wang Yue ${ }^{1}$, Duan Wei ${ }^{1}$, Zhang Qin ${ }^{1}$, Yang Qingwu ${ }^{1 *}$, Liang Xiaojun ${ }^{3^{*}}$ and Bai Yang ${ }^{4^{*}}$

\begin{abstract}
Background: Vertigo and dizziness (VD) are among the most frequently seen symptoms in clinics and are important for medical students, especially for those in Chinese standardized residency training (SRT). The aim of our study was to examine the PAL method's feasibility in the clinical teaching of VD-related diseases for SRT students in China.

Methods: This is a randomized, controlled, multicenter study. A total of 228 residents were invited to participate in this study, of which 198 completed the program. The students were randomized into two groups, and VD-related diseases were taught using lecture-based learning (control group) or peer-assisted learning (PAL). An examination paper and a rating scale were used to evaluate students' performance in the mastery of VD-related theoretical knowledge and clinical skills, meanwhile students' perceptions, satisfaction, and risk of burnout were also analyzed using a questionnaire. Independent-samples $t$-test and chi-square analysis were performed to evaluate statistical significance for continuous variables and categorical variables, respectively, using SPSS 18.0 software.

Results: The PAL group performed better in mastering theoretical knowledge and clinical skills than the control group. And more students believed that PAL could help improve their personal qualities such as teamwork skills. However, more students reported that PAL increased the risk of burnout.
\end{abstract}

Conclusions: PAL was a suitable and effective method in the clinical teaching of some specialized diseases, especially it was recommended for students who had gained initial knowledge and skills, such as Chinese SRT students.

*Correspondence: yangqwmlys@163.com; 18983204377@163.com; bessie1011@163.com

${ }^{\dagger}$ Xu Rui, Duan Chunmei and He Qian contributed equally to this work.

1 Department of Neurology, The Second Affiliated Hospital, Army Medical University, Chongqing 400037, China

${ }^{3}$ Department of Otolaryngology, The Second Affiliated Hospital, Army

Medical University, Chongqing 400038, China

${ }^{4}$ Department of Otolaryngology, The First Affiliated Hospital, Army

Medical University, Chongqing 400038, China

Full list of author information is available at the end of the article

(c) The Author(s) 2021. Open Access This article is licensed under a Creative Commons Attribution 4.0 International License, which permits use, sharing, adaptation, distribution and reproduction in any medium or format, as long as you give appropriate credit to the original author(s) and the source, provide a link to the Creative Commons licence, and indicate if changes were made. The images or other third party material in this article are included in the article's Creative Commons licence, unless indicated otherwise in a credit line to the material. If material is not included in the article's Creative Commons licence and your intended use is not permitted by statutory regulation or exceeds the permitted use, you will need to obtain permission directly from the copyright holder. To view a copy of this licence, visit http://creativecommons.org/licenses/by/4.0/. The Creative Commons Public Domain Dedication waiver (http://creativeco mmons.org/publicdomain/zero/1.0/) applies to the data made available in this article, unless otherwise stated in a credit line to the data. 
However, we should draw attention to the increased risk of burnout if PAL is intended to be widely used in clinical teaching.

Trial registration: ISRCTN registry, ISRCTN53773239, 05/07/2021, retrospectively registered.

Keywords: Peer group, Internship and residency, Vertigo, Dizziness, Medical education

\section{Introduction}

A new standardized residency training (SRT) program for medical trainees was initiated in China in recent years. This new program aimed to create more standardization in physicians' training and improve the clinical skills of students who previously completed basic theoretical courses and accumulated internship experience in a medical college $[1,2]$. Therefore, it is important for residents to receive systematic training to gain overall improvement in professional competency, including theoretical knowledge and clinical skills [2,3]. This is especially true for some specialized diseases, such as those related to vertigo/dizziness (VD). And in this way, SRT helps to enhance the quality of medical services offered in China.

$\mathrm{VD}$ are among the most frequently reported symptoms in emergency room (ER) consultations. However, distinguishing between serious and benign disorders caused by VD remains challenging in emergency consultations, even for experienced doctors. Additionally, misdiagnosis may be fatal for patients, e.g., serious disorders caused by a posterior stroke [4]. Therefore, the challenges of making a fast and correct diagnosis remind us of the importance of the clinical teaching of VD-related diseases.

As VD may be caused by various diseases presenting diverse symptoms and different pathologies, knowledge of neurology, otolaryngology, ophthalmology and psychology is required; hence, difficulties exist in VD-related diseases' clinical teaching. In traditional teacher-centered education, VD-related diseases have been taught using lecture-based learning (LBL), which often lacks clinical relevance and may predispose learners to information overload [5]. Furthermore, this teaching method is considered to induce passivity and compliance, focusing on a one-way transfer of knowledge [6]. For Chinese SRT students, our experience also indicated that traditional LBL method could not achieve the desired outcomes in the clinical teaching of VD-related diseases. It is, therefore, necessary to try another teaching method to obtain better teaching results.

Peer-assisted learning (PAL), which is defined as "People of similar social groupings who are not professional teachers helping each other to learn and learning themselves by teaching" [7], is an established teaching and learning method used in medical education worldwide [8] that implements peer teaching programs by using students as teachers $[9,10]$. PAL has been widely used in medical education and many benefits have been reported by previous studies [11-18]. A conceptual framework suggests that five processes contribute to the effectiveness of PAL, including "organization and engagement, cognitive conflict, scaffolding and error management, communication, and affect". These processes promote both the "tutor" and the learner to learn in the PAL teaching, and has both cognitive and affective outcomes. Finally, it makes students more aware of PAL method and feeds back to the original five processes in a virtuous cycle, to make PAL more effective [12, 19]. Meanwhile, it was also reported that the secure and collaborative environment in the PAL session also promoted learning [20]. In this way, PAL is mutually beneficial for student tutors and student learners [21-23]. Additionally, unlike traditional LBL, it encourages an active and open exchange of knowledge that improves clinical teaching quality $[5,10]$.

As SRT students in China who have already finished basic theoretical courses and accumulated internship experience, PAL may be suitable for them especially in the clinical teaching of some complicated and specialized diseases, such as VD-related disease. And to the best of our knowledge, PAL was used and compared with traditional teaching methods in other areas of medical education like osteology, dental medicine and nursing [12, 24, 25], there is a lack of research assessing whether PAL can be used in the SRT program or the clinical teaching of VD-related diseases. Therefore, this study aimed to compare teaching results using the PAL method with the LBL method and examine the PAL method's feasibility in the clinical teaching of VD-related diseases for SRT students in China.

\section{Methods \\ Design}

This is a randomized, controlled, multicenter study conducted in three hospitals in Chongqing, China, including four SRT training sites certified by the Chongqing Municipal Health Commission.

\section{Participants and setting}

A total of 228 residents studying at these four SRT training sites between January 2017 and December 2020 were invited to participate in the study (30 residents were ultimately excluded). The inclusion criteria were as follows: 
active residents employed in four training sites who were willing to participate in the training program and assessment procedure. The following exclusion criteria were used: residents who had previously participated in similar curriculum and residents who completed less than $50 \%$ of the training program.

The sample size and power analysis were calculated using "Compare 2 Means: 2-Sample, 2-Sided Equality" tool in the "Power and Sample Size" website (http:// powerandsamplesize.com/Calculators/) according to our preliminary experiment results. Briefly, this calculator uses the following formulas to compute sample size and power, respectively:

$$
\begin{aligned}
& n_{A}=\kappa n_{B} \text { and } \mathrm{n}_{\mathrm{B}}=\left(1+\frac{1}{\kappa}\right)\left(\sigma \frac{\mathrm{z}_{1-\alpha / 2}+\mathrm{z}_{1-\beta}}{\mu_{\mathrm{A}}-\mu_{\mathrm{B}}}\right)^{2} \\
& 1-\beta=\Phi\left(z-z_{1-\alpha / 2}\right)+\Phi\left(-z-z_{1-\alpha / 2}\right), \quad z=\frac{\mu_{A}-\mu_{B}}{\sigma \sqrt{\frac{1}{n_{A}}+\frac{1}{n_{B}}}}
\end{aligned}
$$

Where:

- $\mathrm{k}=\mathrm{n}_{\mathrm{A}} / \mathrm{n}_{\mathrm{B}}$ is the matching ratio

- $\sigma$ is standard deviation

- $\Phi$ is the standard Normal distribution function

- $\Phi^{-1}$ is the standard Normal quantile function

- $\alpha$ is Type I error

- $\quad \beta$ is Type II error, meaning $1-\beta$ is power

Seven attending doctors and 6 senior doctors were invited as directors. All of the residents had completed basic theoretical courses and clinical clerkships in a medical college.

\section{Ethical consideration}

The present study was approved by the Ethics Committee of Xinqiao Hospital, Army Medical University. Participants, who had been previously informed about the project, voluntarily participated this project and agreed with the randomization. Meanwhile participant could quit the project at any time during the research. Written informed consent was obtained from all participants. Meanwhile all the researchers signed a confidentiality agreement regarding the participants' data.

\section{Intervention and control groups}

The students and directors were randomized into two groups: the control (LBL) group and the PAL group. There were 99 residents in each group. The program was completed in 2 weeks.

In the control group, i.e., the PBL group, the program was teacher-centered, and the lecture-based teaching method was used for theoretical knowledge teaching.
The directors taught epidemiology, definitions, classifications, pathophysiology, diagnosis and differential diagnosis, and treatment of VD-related diseases. For clinical practice teaching, different typical cases of VD-related patients were chosen and taught by the directors.

In the PAL group, the 99 students were randomized into 33 subgroups (3 students in one subgroup). One student in the subgroup was selected as the tutor by other members. All of the selected student tutors received routine tutor training that comprised three individual 3-h sessions led by directors, as previously reported [10]. After that, the students learned knowledge of VD-related diseases, and then the theoretical knowledge was taught by the student tutor, followed by a group discussion. For clinical practice, the same VD-related patient cases in the control group were chosen. The students performed a medical history inquiry and physical examination by themselves, followed by a group discussion under a student tutor's organization. Finally, each group worked as a team to come up with a diagnosis and treatment plan. The entire process was supervised and commented on by one director.

\section{Instruments and data collection Examination performance}

Examination performance was evaluated before and after teaching.

Mastery of theoretical knowledge was assessed through a written examination paper consisting of 40 single best answer questions that contained four parts ("Concept and classification of VD-related diseases," "Symptoms of different VD-related diseases," "Signs of different VDrelated diseases", and "Treatment of different VD-related diseases", with 2 points awarded for each question and 10 questions for each part) and 2 open-ended questions ("Diagnosis and differential diagnosis", with 10 points for each question). All the questions were chosen from our examination database of neurology. The examination questions in the database were classified into different difficulty levels, and questions were randomly chosen from different levels and constituted a final examination paper for all of the participants enrolled in this research. Details of the paper were shown in supplementary materials.

Clinical skills were also examined by analyzing the case of a standardized patient. The evaluation was performed in five parts: "Medical history inquiry," "Physical examination," "Diagnosis and treatment plan," "Communication skills and care for patients," and "Overall evaluation" (20 points for each part). The rating scale used for clinical skills evaluation of VD-related diseases was given in supplementary materials. 
Examination was performed within 1 week before and after teaching. The examination performance was evaluated by the teaching secretaries (they are also clinical doctors) blinded to the group assignments.

\section{Questionnaire}

Student perceptions and satisfaction The students completed a researcher-made questionnaire (3-point scale with $1=$ improved and $3=$ not improved) asking about their perceptions of the teaching process from 7 aspects. This questionnaire included items about "Study activeness," "Mastery of theoretical knowledge," "Efficiency of learning," "Application of clinical knowledge," "Communication skills," "Self-study ability," and "Self-confidence and teamwork skills." The items and scopes of the questionnaire were chosen according to previous report $[1,26]$ and our own teaching experience.

Additionally, we investigated satisfaction and the risk of burnout using different teaching methods with a researcher-made questionnaire (3-point scale with $1=$ agree and $3=$ disagree).

Questionnaire was completed within 1 week after teaching.

Validity and reliability The responses on the scale in the questionnaire were collected, and the validity and reliability were analyzed using SPSS 18.0 software.

\section{Statistical methods}

The basic characteristics of each cohort are presented as the mean $\pm S D$. For continuous variables (such as score), an independent-samples $t$-test was used to evaluate statistical significance between groups, while a pairedsamples $t$-test was used to analyze the paired data (pretest and posttest). For categorical variables (such as sex), chi-square analysis was used to evaluate statistical significance. The statistical method used for variable with three categories was also chi-square analysis in Descriptive Statistics $\rightarrow$ Crosstabs. If any cells had expected count less than 5, Fisher's Exact Test would be applied. $P$-values less than 0.05 were considered significant. Analyses were performed with SPSS 18.0 software.

\section{Results}

\section{Characteristics of residents}

A power analysis was carried out to calculate the sample size (power $=0.9, n=110$; power $=0.8, n=83$ ). And A total of 228 residents were invited to participate in this study, of which 21 residents were excluded and 9 residents were dropped out during research process (details were specified in Fig. 1). Process of randomization and definitive participation of students is shown in Fig. 1. Residents were from different specialties at four separate training sites. The demographic and work characteristics of the residents are summarized in Table 1. The Control group and PAL group's mean ages were similar (24.65years vs. 24.47years). Other important basic characteristics (such as work experience, degree of education, and year in SRT) that might lead to the risk of bias were all assessed. The results indicated that the two groups' basic characteristics were similar without significant differences $(p>0.05)$.

\section{Examination performance}

Regarding mastery of theoretical knowledge, it was found that before teaching, no significant differences in the scores were found between the Control group and the PAL group (except for "Diagnosis and differential diagnosis," Table 2). After teaching, test scores were significantly higher in both groups compared with before teaching (statistical data not shown in the Table 2). However, students in the PAL group performed significantly better in examining theoretical knowledge than those in the Control group. The PAL group had higher scores than the Control group in the following five parts: "Concept and classification of VD-related diseases" (Table 2: Control vs. PAL, $13.01 \pm 3.27$ vs. $\left.15.23 \pm 2.84 ; *{ }^{*} p<0.01\right)$, "Symptoms of different VD-related diseases" (Table 2: Control vs. PAL, $11.35 \pm 2.57$ vs. $12.53 \pm 2.13$; $\left.{ }^{* *} p<0.01\right)$, "Signs of different VD-related diseases" (Table 2: Control vs. PAL, $11.49 \pm 2.67$ vs. $15.58 \pm 2.68 ; * *<0.01)$, "Diagnosis and differential diagnosis" (Table 2: Control vs. PAL, $12.59 \pm 2.06$ vs. $\left.13.85 \pm 1.97 ;{ }^{* *} p<0.01\right)$, and "Treatment of different VD-related diseases" (Table 2: Control vs. PAL, $11.17 \pm 2.63$ vs. $13.43 \pm 2.68 ; * *<0.01)$. The average total score of theoretical knowledge for the PAL group was 70.62, which was also significantly higher than that of the Control group (average score: 59.62, ${ }^{* * *} p<0.01$; Table 2).

Improvements in clinical skills after teaching were also investigated. As shown in Table 3, the exam results revealed that both groups' scores increased after teaching. More importantly, it was found that the average scores for "Medical history inquiry," "Physical examination," "Diagnosis and treatment plan," "Communication skills and care for patients," and "Overall evaluation" in the PAL group were 15.08, 15.13, 15.53, 13.81 and 14.76 points, respectively, which were higher than those in the Control group $(13.11,12.69,11.27,12.19$ and 13.09, respectively, * $p<0.01$; Table 3$)$. The PAL group's average total score also increased significantly compared 


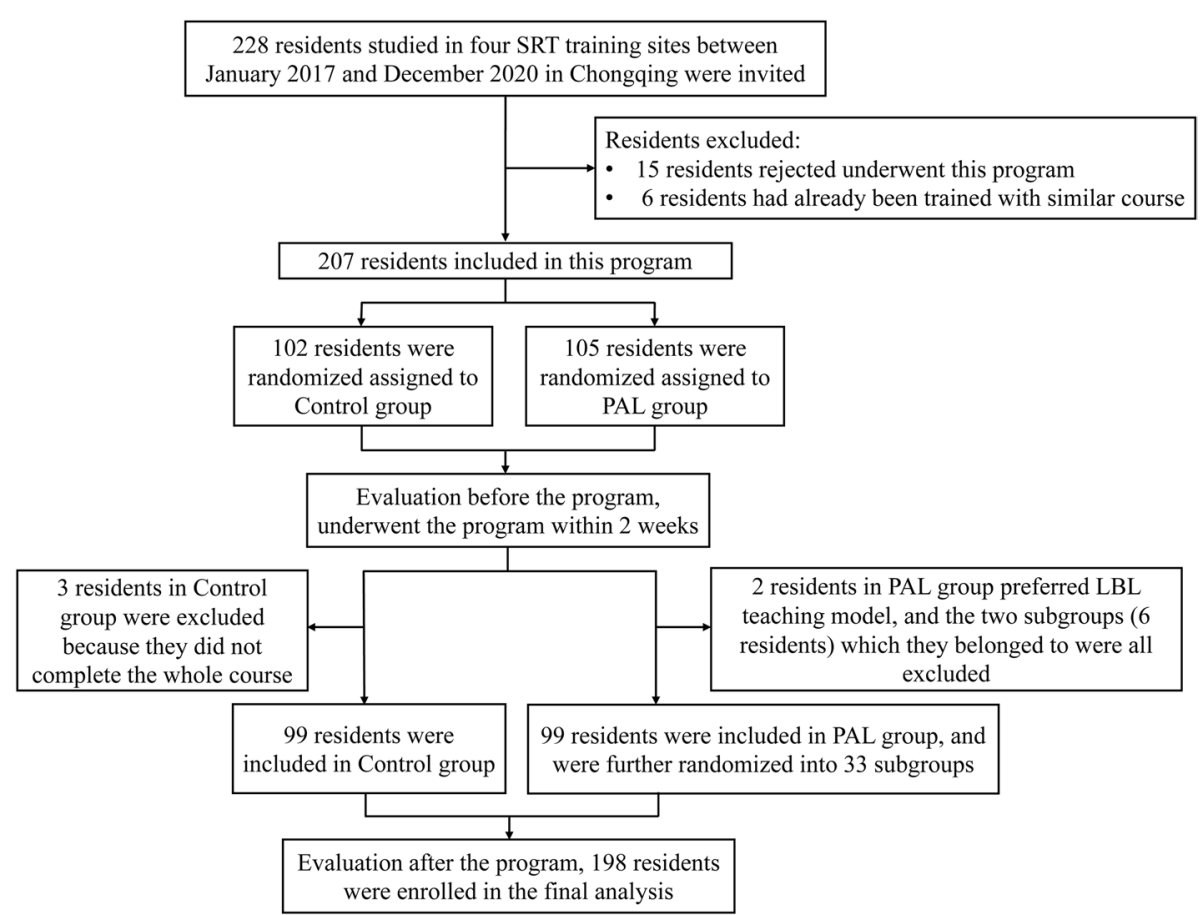

Fig. 1 Flow chart of the study. Abbreviations: SRT: standardized residency training; PAL: peer-assisted learning; LBL: lecture-based learning

Table 1 Demographic and work characteristics of residents and statistical analysis

\begin{tabular}{|c|c|c|c|}
\hline Variables & $\begin{array}{l}\text { Control }(n=99) \\
\text { No. }(\%)\end{array}$ & $\begin{array}{l}\text { PAL }(n=99) \\
\text { No. }(\%)\end{array}$ & $P^{*}$ \\
\hline Age (years, mean $\pm S D$ ) & $24.65 \pm 2.06$ & $24.47 \pm 2.14$ & 0.70 \\
\hline $\operatorname{Sex}(M / F)$ & & & 0.39 \\
\hline Male & $45(45.45)$ & $51(51.51)$ & \\
\hline Female & $54(54.55)$ & $48(48.48)$ & \\
\hline Work experience before SRT & & & 0.64 \\
\hline Yes & $11(11.11)$ & $9(9.09)$ & \\
\hline None & $88(88.89)$ & $90(90.91)$ & \\
\hline Education & & & 0.49 \\
\hline Bachelor's degree & $60(60.61)$ & $68(68.69)$ & \\
\hline Master's degree & $32(32.32)$ & $25(25.25)$ & \\
\hline Doctoral degree & $7(7.07)$ & $6(6.06)$ & \\
\hline Year in SRT & & & 0.57 \\
\hline 1st year & $32(32.32)$ & $39(39.39)$ & \\
\hline 2nd year & $35(35.35)$ & $30(30.30)$ & \\
\hline 3rd year & $32(32.32)$ & $30(30.30)$ & \\
\hline $\begin{array}{l}\text { Recognition on necessity of } \\
\text { SRT }\end{array}$ & & & 0.74 \\
\hline Unnecessary & $10(10.10)$ & $9(9.09)$ & \\
\hline Neutral & $65(65.66)$ & $70(70.71)$ & \\
\hline Necessary & $24(24.24)$ & $20(20.20)$ & \\
\hline
\end{tabular}

*Independent-samples $t$-test for continuous variables (age); Chi-square analysis for categorical variables (sex) with that of the Control group (74.30 vs. $62.35,{ }^{* * *} p<0.01$, Table 3).

After the study was finished, power was also calculated and the power was 0.99 for the primary outcome, i.e., examination performance.

\section{Questionnaire Validity and reliability}

The validity and reliability were analyzed, and KaiserMeyer-Olkin (KMO) for Control group and PAL group were 0.907 and 0.888 , respectively. Meanwhile Cronbach's Alpha for Control group and PAL group were 0.974 and 0.968 , respectively.

\section{Student perceptions and satisfaction}

When the teaching program finished, a list of potential concerns focusing on different attitudes and effects was ranked through a questionnaire, which was evaluated by the students. It revealed that more students believed that PAL could help improve their "Study activeness," "Mastery of theoretical knowledge," "Efficiency of learning," "Application of clinical knowledge," "Self-study ability", and "Self-confidence and teamwork skills" (Table 4). More students in the PAL group (55.56\%) than that in the 
Table 2 Comparison of scores (theoretical knowledge) between two groups before and after teaching

\begin{tabular}{|c|c|c|c|c|c|c|c|c|}
\hline \multirow[t]{2}{*}{ Items } & \multicolumn{4}{|l|}{ Pretest } & \multicolumn{4}{|l|}{ Posttest } \\
\hline & Control & PAL & $t$ & $P$ & Control & PAL & $t$ & $P$ \\
\hline Concept and classification of VD-related diseases & $8.85 \pm 3.00$ & $8.24 \pm 2.80$ & 1.47 & 0.14 & $13.01 \pm 3.27$ & $15.23 \pm 2.84$ & -5.10 & $<0.01$ \\
\hline Symptoms of different VD-related diseases & $8.08 \pm 3.17$ & $8.00 \pm 2.41$ & 0.20 & 0.84 & $11.35 \pm 2.57$ & $12.53 \pm 2.13$ & -3.49 & $<0.01$ \\
\hline Signs of different VD-related diseases & $7.96 \pm 1.67$ & $7.68 \pm 2.09$ & 1.05 & 0.29 & $11.49 \pm 2.67$ & $15.58 \pm 2.68$ & -10.72 & $<0.01$ \\
\hline Treatment of different VD-related diseases & $8.44 \pm 2.28$ & $8.34 \pm 2.10$ & 0.32 & 0.75 & $11.17 \pm 2.63$ & $13.43 \pm 2.68$ & -5.99 & $<0.01$ \\
\hline Diagnosis and differential diagnosis & $9.32 \pm 1.92$ & $8.66 \pm 1.73$ & 2.56 & 0.01 & $12.59 \pm 2.06$ & $13.85 \pm 1.97$ & -4.41 & $<0.01$ \\
\hline Total score & $42.66 \pm 6.68$ & $40.92 \pm 5.77$ & 1.96 & 0.06 & $59.62 \pm 6.78$ & $70.62 \pm 6.03$ & -12.06 & $<0.01$ \\
\hline
\end{tabular}

Table 3 Comparison of scores (clinical skills) between two groups before and after teaching

\begin{tabular}{|c|c|c|c|c|c|c|c|c|}
\hline \multirow[t]{2}{*}{ Items } & \multicolumn{4}{|l|}{ Pretest } & \multicolumn{4}{|l|}{ Posttest } \\
\hline & Control & PAL & $t$ & $P$ & Control & PAL & $t$ & $P$ \\
\hline Medical history inquiry & $8.93 \pm 2.35$ & $7.44 \pm 2.00$ & 4.79 & $<0.01$ & $13.11 \pm 2.58$ & $15.08 \pm 1.54$ & -6.51 & $<0.01$ \\
\hline Physical examination & $8.11 \pm 2.01$ & $8.00 \pm 2.58$ & 0.34 & 0.74 & $12.69 \pm 2.32$ & $15.13 \pm 2.01$ & -7.92 & $<0.01$ \\
\hline Diagnosis and treatment plan & $6.86 \pm 2.21$ & $8.51 \pm 1.53$ & -6.09 & $<0.01$ & $11.27 \pm 2.48$ & $15.53 \pm 1.71$ & -14.04 & $<0.01$ \\
\hline Communication skills and care for patients & $7.27 \pm 2.69$ & $8.37 \pm 1.93$ & -3.31 & $<0.01$ & $12.19 \pm 2.24$ & $13.81 \pm 2.28$ & -5.04 & $<0.01$ \\
\hline Overall evaluation & $10.25 \pm 1.45$ & $8.43 \pm 1.14$ & 9.81 & $<0.01$ & $13.09 \pm 1.33$ & $14.76 \pm 1.18$ & -9.32 & $<0.01$ \\
\hline Total score & $41.42 \pm 6.49$ & $40.76 \pm 4.64$ & 0.83 & 0.41 & $62.35 \pm 6.53$ & $74.30 \pm 5.25$ & -14.19 & $<0.01$ \\
\hline
\end{tabular}

Table 4 Residents' perceptions of the teaching process [n (\%)]

\begin{tabular}{|c|c|c|c|c|c|c|c|c|}
\hline \multirow[t]{2}{*}{ Items } & \multicolumn{3}{|l|}{ Control } & \multicolumn{3}{|l|}{ PAL } & \multirow[t]{2}{*}{$x^{2}$} & \multirow[t]{2}{*}{$P$} \\
\hline & Improved & Neutral & Not Improved & Improved & Neutral & Not Improved & & \\
\hline Study activeness & $45(45.45 \%)$ & $45(45.45 \%)$ & $9(9.09 \%)$ & $60(60.61 \%)$ & $37(37.37 \%)$ & $2(2.02 \%)$ & 7.38 & 0.03 \\
\hline Mastery of theoretical knowledge & $30(30.30 \%)$ & 49 (49.49\%) & $20(20.20 \%)$ & $62(62.63 \%)$ & $36(36.36 \%)$ & $1(1.01 \%)$ & 30.31 & $<0.01$ \\
\hline Efficiency of learning & $30(30.30 \%)$ & $52(52.53 \%)$ & $17(17.17 \%)$ & $63(63.64 \%)$ & $36(36.36 \%)$ & $0(0 \%)$ & 31.62 & $<0.01$ \\
\hline Application of knowledge in the clinical & $32(32.32 \%)$ & $51(51.51 \%)$ & $16(16.16 \%)$ & $57(57.58 \%)$ & $40(40.40 \%)$ & $2(2.02 \%)$ & 19.24 & $<0.01$ \\
\hline Communication skills & $23(23.23 \%)$ & $69(69.70 \%)$ & $7(7.07 \%)$ & $25(25.25 \%)$ & $70(70.71 \%)$ & $4(4.04 \%)$ & 0.91 & 0.64 \\
\hline Self-study ability & $25(25.25 \%)$ & $49(49.49 \%)$ & $25(25.25 \%)$ & $40(40.40 \%)$ & $59(59.60 \%)$ & $0(0 \%)$ & 29.39 & $<0.01$ \\
\hline Self-confidence \& Teamwork skills & $25(25.25 \%)$ & $59(59.60 \%)$ & $15(15.15 \%)$ & $50(50.51 \%)$ & 49 (49.49\%) & $0(0 \%)$ & 24.26 & $<0.01$ \\
\hline
\end{tabular}

Control group (44.44\%) were satisfied and recommended how they were taught. However, it should also be noted that $62.63 \%$ of students reported that PAL increased the risk of burnout, which was more than that of students in the Control group $\left(19.19 \%,{ }^{* *} p<0.01\right.$, Table 5).

\section{Discussion}

VD-related diseases are traditionally taught using the LBL method, which is widely used in medical education. The LBL method has recently been considered a oneway transfer of knowledge that may predispose learners to information overload and promote a passive learning culture $[5,6]$. Our previous experience also indicated that clinical teaching of VD-related diseases using the traditional LBL method did not achieve the desired outcomes, and more variety in teaching approaches was needed.

In this study we implemented PAL in the clinical teaching of VD-related diseases for SRT students in China. Compared with the traditional LBL method, the PAL method promoted mastery of VD-related knowledge and skills and improved students' personal qualities. PAL activities encompass "People from similar social groupings who are not professional teachers helping each other to learn and learning themselves by teaching" [27]. As 
Table 5 Risk for burnout and satisfaction of different methods [n (\%)]

\begin{tabular}{|c|c|c|c|c|c|c|c|c|}
\hline \multirow[t]{2}{*}{ Items } & \multicolumn{3}{|l|}{ Control } & \multicolumn{3}{|l|}{ PAL } & \multirow[t]{2}{*}{$x^{2}$} & \multirow[t]{2}{*}{$P$} \\
\hline & Agree & Neutral & Disagree & Agree & Neutral & Disagree & & \\
\hline \multirow[t]{2}{*}{ Increased risk for burnout } & $19(19.19 \%)$ & $65(65.66 \%)$ & $15(15.15 \%)$ & $62(62.63 \%)$ & $37(37.37 \%)$ & $0(0 \%)$ & 45.51 & $<0.01$ \\
\hline & Recommended & Neutral & Not Recommended & Recommended & Neutral & Not Recommended & $x^{2}$ & $P$ \\
\hline $\begin{array}{l}\text { Satisfaction and } \\
\text { recommendation of PAL } \\
\text { method }\end{array}$ & $44(44.44 \%)$ & $54(54.55 \%)$ & $1(1.01 \%)$ & $55(55.56 \%)$ & $43(43.43 \%)$ & $1(1.01 \%)$ & 9.34 & $<0.01$ \\
\hline
\end{tabular}

mentioned above, students participating in SRT have already finished basic theoretical courses and accumulated internship experience; thus, initial knowledge and skills are gained, and it is suitable for the implementation of PAL in the SRT program. Previous similar articles reported application of PAL for undergraduate students' education in Australia, India, Pakistan, etc. And in these studies PAL was used in the area of radiography, osteology, and dental education, respectively [12, 24, 28]. However, to the best of our knowledge, few studies assess how the PAL method works in SRT in China, as well as clinical teaching of VD-related disease.

In our study, VD-related disease is considered complicated and difficult to learn for residents. We tried to teach students in this new way because student tutors and student learners had a similar knowledge base and learning experiences, i.e., they "were on the same wavelength" [10]. Therefore, student tutors could determine which part of VD-related knowledge was challenging to learn for student learners. With the help of directors, student tutors could explain key points in a way that was easier for student learners to understand [23]. Additionally, student tutors and student learners have similar social roles, which encouraged an open exchange of ideas and concerns. In this way, student tutors and student learners would have sufficient discussion opportunities during the teaching process and learn from each other. Our study confirmed that the PAL method finally promoted mastery of VD-related knowledge and skills. In line with our study, PAL group showing higher mean scores in osteology teaching, compared with traditional didactic methods [12]. Not only in the area of medicine, but also PAL was demonstrated a useful tool in the other areas of health sciences. For example, Nasenien et al. demonstrated that PAL was a useful tool for teaching basic abdominal ultrasound [29]; George reported that PAL was a beneficial teaching strategy for nursing students [25]. However, inconsistent with our results, Ambreen et al. reported that in dental education, test scores, academic performance and overall learning in PAL sessions was not higher than control group. But they still recommended that PAL could be utilized as an important supplement to synchronous teaching tele-presence, especially during current pandemic situation [24].

When a new method is implemented in clinical teaching, results on student satisfaction and perceptions should be noted, as student satisfaction and engagement lead to achieving program outcomes [30-32]. In our study, student perceptions and satisfaction were investigated using a self-evaluated questionnaire. According to students' perceptions, mastery of professional skills was promoted, and qualities such as self-study, self-confidence, and teamwork skills were improved. In line with our findings, Wawrzynski et al. reported that peer education improved students' public speaking skills, organizational abilities, and individual self-confidence [33]. However, a potential concern raised is the increased risk of burnout. Burnout is a common experience for medical residents that leads to many challenges, including mental health issues such as suicidal tendencies and physical symptoms such as fatigue and headaches [34-38]. In our study, although most of the students had accepted the PAL method, it should be noted that PAL increased the risk of burnout. This phenomenon can be explained by long hours of self-study after class, concurrent with preparation for teaching and class discussion, which might also increase studying-related pressure. Therefore, we should draw attention to the increased risk of burnout if PAL is intended to be widely used in clinical teaching. Same concern was also raised by other researchers, Hundertmark et al. comprehensively quantified tutors' stress and described frequent stressors in the PAL [39], and Matthew et al. proposed that support and feedback developed competence and confidence and reduced stress and anxiety [40].

Although PAL has been used worldwide, the present study is, to our knowledge, the first randomized, controlled, multicenter study to explore its implementation in SRT programs in China and the first study to explore its potential application in the clinical teaching of VD-related diseases. However, our study has some limitations. For instance, student tutors were chosen by students rather than arranged randomly, therefore, "high achievers" with high confidence who were often selected as tutors while students with low confidence might have 
been ignored. However, those who did not volunteer are probably the ones who needed the exercise most. Therefore, improving the personal skills of students with low confidence by having them work as student tutors could not be investigated in this study.

\section{Conclusions}

The paper describes implementing PAL in the clinical teaching of VD-related diseases for SRT students in China. Compared with the traditional LBL method, the PAL method promoted mastery of VD-related knowledge and skills and improved students' personal qualities, such as self-confidence, communication, self-study, and teamwork skills. Most of the students were satisfied and recommended the PAL method. However, our study also reminded us to draw attention to the increased risk of burnout when teaching using the PAL method. Overall, our findings suggested that PAL was a suitable and effective method in the clinical teaching of some specialized diseases, especially for students who had already gained initial knowledge and skills, such as SRT students in China.

\section{Abbreviations}

SRT: Standardized residency training; VD: Vertigo and dizziness; LBL: Lecturebased learning; PAL: Peer-assisted learning.

\section{Supplementary Information}

The online version contains supplementary material available at https://doi. org/10.1186/s12909-021-02969-1.

Additional file 1: Table S1. The paper used for theoretical knowledge examination of VD-related diseases. Table S2. The rating scale used for clinical skills evaluation of VD-related diseases.

\section{Acknowledgements}

The authors thank all the participants in this study.

\section{Authors' contributions}

X.R., D.C.M., H.Q., Y.Q.W., L.X.J. and B.Y. designed the experiments and drafted the manuscript, helped teaching secretaries to perform the statistical analyses. X.R., D.C.M., H.Q., M.Z.Y., W.G., L.S., G.M., C.X.Y., W.Y., D.W., Z.Q., Y.Q.W., L.X.J. and B.Y. performed the experiments. All authors read and approved the final manuscript.

\section{Funding}

This work was supported by National Natural Science Foundation for Young Scientists of China (No. 81901271); Miao Pu project of Army Medical University (2017R016); Major Clinical Program from Xinqiao Hospital (2018JSLC0024).

\section{Availability of data and materials}

The data analyzed under the current study are available from the corresponding author on reasonable request (Bai Yang, Email: bessie1011@163.com).

\section{Declarations}

Ethics approval and consent to participate

The present study was approved by the Ethics Committee of Xinqiao Hospital, Army Medical University. All methods were carried out in accordance with relevant guidelines and regulations. Written informed consent was obtained from all participants.

\section{Consent for publication}

Not applicable.

\section{Competing interests}

The authors declare no conflicts of interests.

\section{Author details}

${ }^{1}$ Department of Neurology, The Second Affiliated Hospital, Army Medical University, Chongqing 400037, China. ${ }^{2}$ Department of Neurology, Chongqing Traditional Chinese Medicine Hospital, Chongqing 400021, China. ${ }^{3}$ Department of Otolaryngology, The Second Affiliated Hospital, Army Medical University, Chongqing 400038, China. ${ }^{4}$ Department of Otolaryngology, The First Affiliated Hospital, Army Medical University, Chongqing 400038, China.

Received: 6 July 2021 Accepted: 16 July 2021

Published online: 14 October 2021

\section{References}

1. Huang L, Caspari JH, Sun X, Thai J, Li Y, Chen FZ, et al. Risk and protective factors for burnout among physicians from standardized residency training programs in Shanghai: a cross-sectional study. BMC Health Serv Res. 2020;20(1):965.

2. Yang Y, Li LY, Sang LW, Yang BY, Zhu PY, Dai L, et al. An observation of a resident-as-teacsher combined with tutor guided hysteroscopy teaching program for standardized residency training (SRT) in obstetrics and gynecology. J Healthc Eng. 2020;2020:8855099.

3. He Y, Qian W, Shi L, Zhang K, Huang J. Standardized residency training: an equalizer for residents at different hospitals in Shanghai, China? Int J Health Plann Manag. 2020;35(2):592-605.

4. Jahn K, Kreuzpointner A, Pfefferkorn T, Zwergal A, Brandt T, Margraf A. Telling friend from foe in emergency vertigo and dizziness: does season and daytime of presentation help in the differential diagnosis? J Neurol. 2020;267(1):118-25

5. Nicolaou PA, El Saifi M. The impact of using virtual patients in preclinical pharmacology teaching. Adv Physiol Educ. 2020;44(3):363-9.

6. Zeng HL, Chen DX, Li Q, Wang XY. Effects of seminar teaching method versus lecture-based learning in medical education: a meta-analysis of randomized controlled trials. Med Teach. 2020;42(12):1343-9.

7. Ologunde R, Rabiu R. Students as teachers: the value of peer-led teaching. Perspect Med Educ. 2014;3(1):61-2.

8. Ten Cate O. Practice report / Bericht aus der praxis: peer teaching: from method to philosophy. Z Evid Fortbild Qual Gesundhwes. 2017;127-128:85-7.

9. Bulte C, Betts A, Garner K, Durning S. Student teaching: views of student near-peer teachers and learners. Med Teach. 2007;29(6):583-90.

10. Bugaj TJ, Blohm M, Schmid C, Koehl N, Huber J, Huhn D, et al. Peerassisted learning (PAL): skills lab tutors' experiences and motivation. BMC Med Educ. 2019;19(1):353.

11. Agius A, Stabile I. Undergraduate peer assisted learning tutors' performance in summative anatomy examinations: a pilot study. Int J Med Educ. 2018;9:93-8.

12. Anantharaman LT, Ravindranath $Y$, Dayal S, Shankar N. Peer-assisted learning versus didactic teaching in osteology for first-year Indian undergraduate medical students: a quasi-experimental study. Surg Radiol Anat. 2019;41(10):1163-71

13. Awasthi S, Yadav KK. Assessment of the acceptance and effectiveness of peer-assisted learning in pediatrics. Int J Appl Basic Med Res. 2015;5(Suppl 1):S3-6.

14. El Tantawi MM, Abdelaziz H, AbdelRaheem AS, Mahrous AA. Using peerassisted learning and role-playing to teach generic skills to dental students: the health care simulation model. J Dent Educ. 2014;78(1):85-97.

15. Jauregui J, Bright S, Strote J, Shandro J. A novel approach to medical student peer-assisted learning through case-based simulations. West J Emerg Med. 2018;19(1):193-7.

16. Sahoo S, Venkatesan P, Myint KT, Moe S. Peer-assisted learning activities during undergraduate ophthalmology training: how the medical 
students of Asia Pacific region perceive. Asia Pac J Ophthalmol (Phila). 2015;4(2):76-9.

17. Srivastava TK, Waghmare LS, Mishra VP, Rawekar AT, Quazi N, Jagzape AT. Peer teaching to foster learning in physiology. J Clin Diagn Res. 2015;9(8):JC01-6.

18. Tai JH, Canny BJ, Haines TP, Molloy EK. The role of peer-assisted learning in building evaluative judgement: opportunities in clinical medical education. Adv Health Sci Educ Theory Pract. 2016;21 (3):659-76.

19. Topping K. Trends in peer learning. Educ Psychol. 2005;25:631-45.

20. Tamachi S, Giles JA, Dornan T, Hill EJR. "You understand that whole big situation they're in": interpretative phenomenological analysis of peerassisted learning. BMC Med Educ. 2018;18(1):197.

21. Soriano RP, Blatt B, Coplit L, CichoskiKelly E, Kosowicz L, Newman L, et al. Teaching medical students how to teach: a national survey of students-as-teachers programs in U.S. medical schools. Acad Med. 2010;85(11):1725-31.

22. Dandavino M, Snell L, Wiseman J. Why medical students should learn how to teach. Med Teach. 2007;29(6):558-65.

23. YuTC, Wilson NC, Singh PP, Lemanu DP, Hawken SJ, Hill AG. Medical students-as-teachers: a systematic review of peer-assisted teaching during medical school. Adv Med Educ Pract. 2011;2:157-72.

24. Ehsan AA. Peer-assisted learning (PAL) as an instructional tool in undergraduate dental education. J Coll Physicians Surg Pak. 2020:30(11):1184-7.

25. George TP, Gainey KL, Kershner SH, Weaver DL, Hucks JM. Junior and senior nursing students: a near-peer simulation experience. J Nurs Educ. 2020;59(1):54-6.

26. Miao Y, Pengpeng W, Bing $H$, Yue S. Influencing factors of residents'satisfaction with MOOCs in standardized residency training. Chin J Med Edu Res. 2020;19(8):949-52.

27. Burgess A, van Diggele C, Roberts C, Mellis C. Planning peer assisted learning (PAL) activities in clinical schools. BMC Med Educ. 2020;20(Suppl 2):453.

28. Lee K, Baird M, Lewis S, McInerney J, Dimmock M. Computed tomography learning via high-fidelity simulation for undergraduate radiography students. Radiography (Lond). 2020;26(1):49-56.

29. Nourkami-Tutdibi N, Tutdibi E, Schmidt S, Zemlin M, Abdul-Khaliq H, Hofer M. Long-term knowledge retention after peer-assisted abdominal ultrasound teaching: is PAL a successful model for achieving knowledge retention? Ultraschall Med. 2020;41(1):36-43.
30. Madi M, Hamzeh H, Griffiths M, Rushton A, Heneghan NR. Exploring taught masters education for healthcare practitioners: a systematic review of literature. BMC Med Educ. 2019;19(1):340.

31. Constantine M, Carpenter C. Bringing Masters'level skills to the clinical setting: what is the experience like for graduates of the Master of Science in manual therapy programme? Physiother Theory Pract. 2012;28(8):595-603.

32. Bearn DR, Chadwick SM. Problem-based learning in postgraduate dental education: a qualitative evaluation of students' experience of an orthodontic problem-based postgraduate programme. Eur J Dent Educ. 2010;14(1):26-34.

33. Wawrzynski MRLC, Straker EJ. Learning outcomes for peer educators: the national survey on peer education. New Dir Stud Serv. 2011;133:17-27.

34. Kimo Takayesu J, Ramoska EA, Clark TR, Hansoti B, Dougherty J, Freeman $W$, et al. Factors associated with burnout during emergency medicine residency. Acad Emerg Med. 2014;21(9):1031-5.

35. Chen KY, Yang CM, Lien CH, Chiou HY, Lin MR, Chang HR, et al. Burnout, job satisfaction, and medical malpractice among physicians. Int J Med Sci. 2013;10(11):1471-8.

36. Kwah J, Weintraub J, Fallar R, Ripp J. The effect of burnout on medical errors and professionalism in first-year internal medicine residents. J Grad Med Educ. 2016;8(4):597-600.

37. Thomas NK. Resident burnout. JAMA. 2004;292(23):2880-9.

38. Dewa CS, Loong D, Bonato S, Thanh NX, Jacobs P. How does burnout affect physician productivity? A systematic literature review. BMC Health Serv Res. 2014;14:325.

39. Hundertmark J, Alvarez S, Loukanova S, Schultz JH. Stress and stressors of medical student near-peer tutors during courses: a psychophysiological mixed methods study. BMC Med Educ. 2019;19(1):95.

40. Carey MC, Kent B, Latour JM. Experiences of undergraduate nursing students in peer assisted learning in clinical practice: a qualitative systematic review. JBI Database System Rev Implement Rep. 2018;16(5):1190-219.

\section{Publisher's Note}

Springer Nature remains neutral with regard to jurisdictional claims in published maps and institutional affiliations.
Ready to submit your research? Choose BMC and benefit from:

- fast, convenient online submission

- thorough peer review by experienced researchers in your field

- rapid publication on acceptance

- support for research data, including large and complex data types

- gold Open Access which fosters wider collaboration and increased citations

- maximum visibility for your research: over $100 \mathrm{M}$ website views per year

At BMC, research is always in progress.

Learn more biomedcentral.com/submissions 